\title{
QUALIDADE TOTAL NA AVICULTURA DE CORTE: UMA ANÁLISE DA PERCEPÇÃO DOS PRODUTORES RURAIS INTEGRADOS DE UMA AGROINDÚSTRIA
}

\author{
Total quality in the poultry: an analysis of farmers \\ integrated to agro-industrial company' perception
}

\author{
Nívia Maria Berta ${ }^{1}$ \\ Gabriel Murad Velloso Ferreira ${ }^{2}$ \\ Edson Talamini ${ }^{3}$
}

\begin{abstract}
Resumo
Esta pesquisa teve como objetivo analisar a expectativa e a percepção dos integrados de uma Agroindústria com relação aos requisitos do programa de Qualidade Total Rural (QTR). Nesta perspectiva, o trabalho tem como fundamentação teórica o constructo da qualidade, englobando: programas de qualidade, qualidade total, qualidade total rural, programa $5 \mathrm{~S}$ e avicultura no Brasil. Para o alcance do objetivo, foi realizado um estudo de caso em uma agroindústria de grande porte, e os dados foram obtidos por meio de questionários semiestruturados, com base nos requisitos do Programa de Qualidade Total Rural, os quais foram aplicados a uma amostra aleatória probabilística dos integrados da Agroindústria. A análise dos dados foi realizada de forma comparativa entre a expectativa e a percepção dos produtores rurais com relação ao programa de Qualidade Total Rural, utilizando-se de estatísticas descritivas. Os resultados obtidos, de forma geral, indicaram que os cinco sensos que compõem o programa QTR apresentaram, em média, a expectativa superior à percepção. Ou seja, os integrados
\end{abstract}

\footnotetext{
${ }^{1}$ Bacharel em Administração Industrial (FABE), pós-graduanda em Gestão Empresarial e Liderança (FABE), Rua Alagoas, 41, Santa Helena, Marau, RS, Brasil-99150-000. E-mail: niviab@ibest.com.br

${ }^{2}$ Mestre em Agronegócios (CEPAN/UFRGS), Professor da FABE e UPF, Rua José Posser, 275, Marau, RS, Brasil 99150-000. E-mail: gabriel@fabemarau.edu.br

${ }^{3}$ Doutor em Agronegócios (CEPAN/UFRGS), Professor da UPF e UNIPLAC, Rua Padres Capuchinhos, 1048, Marau, RS, Brasil-99150-000. E-mail: edsontalamini@terra.com.br
} 
reconhecem a importância de cada senso dentro do Programa QTR para um melhor rendimento do trabalho e obtenção de maior qualidade, porém, não desempenham cada requisito nos níveis necessários, considerados por eles. integrada.

Palavras-chave: qualidade total; 5S; qualidade percebida; avicultura de corte; produção

\begin{abstract}
The present research has as main objective to analyze the expectancy and perception of farmers integrated to Agro-industrial Company regarding the requisites of the Rural Total Quality Program (RTQP). In this perspective, the research has as theoretical support a quality analysis framework. A case study was accomplished from primary and secondary data. The primary data was obtained through a semi-structured questionnaire based on requisites of the Rural Total Quality Program, which was applied to a probabilistic random sample of farmers integrated to Agro-industrial Company. The secondary data was obtained from documents available in the company archives. A comparative analysis between expectancy and perception of farmers related to Rural Total Quality Program was accomplished. The final data analysis was made through descriptive statistical resources. The results, in a general way, show that in all five senses that composes the RTQ Program the expectancy was higher than perception, according the mean value. That is, the farmers recognize the role of each sense into RTQ Program for driving into a better work performance and to improve the quality. However, the same farmers don't carry out each requisite in an appropriate level, as themselves consider it.
\end{abstract}

Keywords: total quality; housekeeping; perceived quality; poultry; integrated production.

\title{
1 Introdução
}

A globalização, com a formação de blocos econômicos, maior velocidade na troca de informações, evolução mais rápida de tecnologias e a crescente complexidade e incerteza do ambiente organizacional, vem influindo decisivamente para a mudança do padrão de concorrência das empresas. Somado a isso, segundo Silva (2005), com o fim da inflação desenfreada na última década, ocorreram mudanças expressivas no padrão de consumo, o que afeta visceralmente o modelo de gestão das empresas, voltando-as para o cliente. A isso se chama de gestão da qualidade.

Nesse sentido, a pressão dos clientes por produtos cada vez melhores, a corrida das empresas em atender a essa pressão, fabricando produtos ou prestando serviços de maior qualidade com preços acessíveis, torna o mercado cada dia mais competitivo. No decorrer do tempo, a busca da qualidade na empresa deixou de ser uma preocupação apenas dos responsáveis pela etapa de fabricação para envolver toda a cadeia produtiva. E isso não é diferente nos diversos setores do agronegócio.

De forma simplificada, o agronegócio engloba todos os elos (da agropecuária, da indústria, de serviço) de um mesmo negócio com o objetivo de atender ao consumidor. Rocha (2005) ainda afirma que agronegócio significa que a matéria-prima sai do campo e inicia um processo de industrialização - quanto mais industrializado, mais valor agregado - depois comercialização, até a mesa do consumidor. E todas essas etapas possuem uma significativa relevância no contexto econômico e social, tanto no Brasil quanto no mundo.

$\mathrm{Na}$ economia brasileira, conforme dados do IBGE (2006), o agronegócio responde por cerca de 34\% do PIB e gera aproximadamente 37\% dos empregos. Em se tratando do comércio exterior brasileiro, o saldo do agronegócio corresponde a mais de $90 \%$, cerca de $\mathrm{R} \$$ 
34 bilhões. É um setor de significativa relevância para a economia e a sociedade, seu enfoque é essencial para retratar as profundas transformações verificadas na agricultura brasileira nas últimas décadas, período no qual, segundo Nunes e Contini (2005), o setor primário deixou de ser um mero provedor de alimentos in natura e consumidor de seus próprios produtos, para ser uma atividade integrada aos setores industriais e de serviços.

Em se tratando da cadeia produtiva da avicultura de corte, objeto de estudo deste trabalho, de acordo com a Associação Brasileira dos Produtores e Exportadores de Frango (ABEF, 2005), a maior parte da carne de frango é produzida em empresas integradas ou cooperativas, cerca de $70 \%$. Cabe ressaltar, ainda, que a produção e o consumo per capita de aves de corte no Brasil vêm aumentando gradativamente. Dados da FAO (2005) reforçam que o Brasil é o terceiro maior produtor e o maior exportador mundial de carne de frango.

Com isso, verifica-se que, no mundo inteiro, a atividade agropecuária está se profissionalizando em níveis nunca vistos e, diante desse cenário, é preciso adotar uma nova forma de administrar o negócio agropecuário em que a propriedade passa a ser uma empresa rural. A idéia de que o mercado precisa mais da empresa do que a empresa do mercado acabou. A resposta imediata foi a melhoria do padrão de qualidade dos produtos e serviços. A qualidade tornou-se condição à permanência no novo ambiente competitivo dos negócios e, em meio a essa economia globalizada, fez com que a preocupação com a qualidade total se tornasse uma necessidade em todas as atividades produtivas.

Nesse contexto, Calegare (1999) afirma que qualidade total é a mobilização contínua de todos os profissionais da Organização, com o objetivo de melhorar a qualidade de suas atividades, de seus produtos e serviços, para satisfazer, ao menor custo, as necessidades de seus clientes internos e externos. O total envolvimento das pessoas implica em revisão de paradigmas (valores e crenças), gerando mudanças de comportamento. Qualidade Total é uma filosofia de gestão empresarial presente, hoje, nas maiores empresas do país e do mundo.

E com base nisso, a Agroindústria estudada vem buscando garantir uma maior e melhor qualidade de seus produtos e bem-estar de seus produtores. Com uma gama de aproximadamente 1.100 integrados na área de avicultura, a empresa busca atingir um patamar de total qualidade diante do mercado competitivo. Após ter implantado o Programa da Qualidade Total nos diversos segmentos de empresa, ela partiu para a aplicação do Programa de Qualidade Total Rural (QTR), no ano de 2000, junto aos seus produtores rurais, ou seja, seus fornecedores de matéria-prima, a carne, que é o principal produto processado pela empresa.

Tendo em vista o acima exposto, o presente trabalho questiona: Qual a qualidade percebida dos integrados com relação ao QTR? Qual a expectativa dos integrados com os requisitos exigidos pelo programa? Qual a percepção dos integrados em se tratando da execução desses requisitos? Quais os requisitos que apresentam uma maior dificuldade em sua aplicação no programa QTR?

As respostas a estas inquietações possibilitarão o planejamento e a execução de ações, de forma integrada na cadeia, com o fim de proporcionar melhoria na qualidade do produto, obtendo maior satisfação do consumidor final, otimizando o desempenho da agroindústria no atual mercado exigente e competitivo, o que possivelmente beneficiará todos os produtores rurais integrados.

\section{Qualidade: uma breve descrição}

Garvin (1992) entende que a qualidade é conhecida, como conceito, há milênios, porém só recentemente surgiu como uma função gerencial formal. Praticamente todas as mudanças em relação à gestão da qualidade, bem como suas diversas abordagens aconteceram 
de forma gradativa, dentro de uma evolução que pode ser considerada regular, e não através de mudanças radicais. Segundo Falconi (1995), a qualidade iniciou no Japão, com Deming e Juran, no período pós-guerra. Nos anos 1960, surgiu a era da inspeção, a preocupação era controlar a qualidade; nos anos 1970, a era do controle estatístico de qualidade, a qualidade era avaliada; nos anos 1980, a era da garantia da qualidade, a grande preocupação era garanti-la; nos anos 1990, a era da gestão da qualidade, buscou-se a melhoria contínua.

Portanto, com o passar dos anos, a qualidade foi ganhando grande importância diante do mercado mundial, os consumidores passaram a ser mais exigentes e as organizações começaram a se preocupar em gerar produtos e serviços que tivessem condições de satisfazer as necessidades dos consumidores sob todos os aspectos. É relevante ressaltar que, de acordo com Garvin (1992), qualidade é um termo que apresenta diversas interpretações e, por isso, é essencial um melhor entendimento para que a qualidade possa assumir um papel estratégico. A forma como a qualidade é definida e entendida em uma organização reflete a forma como é direcionada a produção de bens e serviços.

Como visto anteriormente, com os anos, o termo passou a ser conceituado de maneira diferente, mediante o ponto de vista de seus observadores e estudiosos, em que cada um enfatizou diferentes aspectos e estilos. Diversos autores propuseram uma definição para qualidade, tais como: Deming (1990), Juran (1995), Garvin (1992), Falconi (1995), entre outros.

Deming (1990) enfatiza o lado humano da organização, implementou o uso da organização, da administração da qualidade e desenvolveu um programa que descreve o que é necessário para uma organização sobreviver e ser competitiva.

Falconi (1995) define qualidade em termos de produtos e serviços, significando atender perfeitamente às exigências e necessidades dos clientes/usuários. Falconi (2004) de uma forma mais ampla, menciona que se pode identificar cinco abordagens principais para definição da qualidade: qualidade intrínseca, custo, atendimento/entrega, segurança e moral, as quais serão descritas no decorrer do trabalho. Também é possível identificar, segundo Garvin (1992), oito dimensões ou categorias: desempenho, características, confiabilidade, conformidade, durabilidade, atendimento, estética e qualidade percebida. Para o autor, qualidade é a melhor arma para aumentar lucros e reduzir prejuízos.

Juran (1995), por sua vez, defende que chegar a um consenso sobre o que se entende por qualidade não é simples. Por exemplo, os dicionários técnicos, de um modo geral, trazem uma série de definições. Para os gerentes, nenhuma definição sucinta é realmente precisa, mas uma dessas definições de larga aceitação é que a qualidade é a adequação ao uso.

Diante dos autores citados, qualidade deve ter como objetivo as necessidades presentes e futuras do usuário e também deve adequar-se à finalidade de uso e ter conformidade com as exigências da realidade para que, assim, possa vir a garantir um melhor lucro e minimização dos prejuízos.

É importante mencionar que os conceitos descritos expressam o pensamento de grandes líderes da nova filosofia da qualidade, porém nenhum deles pode ser tomado com exclusividade, pois a qualidade só pode ser entendida quando vinculada à missão da organização. Com isso, pode-se dizer que a qualidade define as atividades prioritárias, cria uma estrutura adequada, desenha processos adequados aos resultados previstos. Entendida como um processo de melhoria continuada, ela deve envolver todos os integrantes do processo desde o fornecedor, funcionários até a gerência, em um esforço solidário de superação de metas, uma relação de benefícios mútuos pode aumentar a capacidade de ambos em agregar valor. 


\subsection{Programas de qualidade e a qualidade total}

As organizações estão enfrentando uma verdadeira competição em relação à questão qualidade que, conforme Juran (1992), passa a ser a razão básica na venda de produtos ou serviços. Segundo o autor, é preciso um planejamento adequado, reexaminando os processos e métodos usados, fazendo mudanças nas deficiências, controlando para que não voltem a acontecer, o que poderá ser concretizado através de um programa de qualidade.

Nesses programas de qualidade, deve-se observar, segundo Juran (1992), as seguintes políticas de qualidade: relações com o cliente, competitividade, melhoramento da qualidade, clientes internos e cumprimento das políticas de qualidade. Dessa maneira, por meio dos programas de desenvolvimento da qualidade pode-se reparar trabalhos mal feitos, sucatear produtos defeituosos, resolver conflitos internos e lidar com reclamações.

Dentre os programas de qualidade, destaca-se a qualidade total, pois extrapola os conceitos de qualidade dos produtos e serviços, estendendo-se desde a limpeza, fornecedores, apresentação e exposição dos produtos, organização do ambiente, clima organizacional até o pós-venda e atendimento ao cliente. Hoje a qualidade total estende-se até a qualidade de vida e do meio ambiente.

Para Falconi (2004), qualidade total é o verdadeiro objetivo de qualquer organização humana, pois satisfaz as necessidades de todas as pessoas. Segundo o autor, a qualidade total contempla cinco dimensões:

- qualidade intrínseca: a qual diz respeito às características do produto como resistência, conforto, sabor, higiene entre outros;

- custo: refere-se ao valor correspondente a este produto e/ou serviço, pois quanto menor o custo do produto e/ou serviço, maior será a satisfação do consumidor;

- atendimento/entrega: contemplando, entre outros, características da relação interpessoal, condições de pagamento, prazo e local de entrega, bem como o serviço pósvenda;

- segurança: no sentido de que o produto e/ou serviço não ocasione qualquer tipo de prejuízo aos clientes, aos trabalhadores que produziram este bem e ao meio ambiente;

- moral: diz respeito à motivação e à auto-estima de todos os trabalhadores da organização. Total,

Segundo Longo e Vergueiro (2003, p. 46), para conquistar um ambiente de Qualidade

é de capital importância satisfazer totalmente seus clientes externos como, também, os internos, pois pessoas insatisfeitas com suas condições e ambientes de trabalho, com pouca valorização profissional e com baixa auto-estima não têm condições de gerar bens e serviços de informação que atendam às necessidades e excedam às expectativas dos clientes.

De acordo com Slack, Chambers e Johnston (2002), a visão de qualidade da operação preocupa-se em tentar atingir as expectativas dos consumidores. Já a visão de qualidade do consumidor é o que ele percebe ser o produto ou serviço, para criar uma visão unificada, a qualidade pode ser definida como o grau de adequação entre as expectativas dos consumidores e a percepção deles do produto ou serviço. Essa idéia permite uma visão de qualidade do consumidor e, portanto, de satisfação com o produto ou serviço como resultado da comparação de suas expectativas quanto ao produto ou serviço, com suas percepções de seu desempenho. Kotler (1998) reforça comentando que a satisfação é função do desempenho percebido e das expectativas. 
Assim, Slack, Chambers e Johnston (2002) apresentam três possibilidades nas relações entre expectativas e percepções dos clientes. Se a experiência com o produto ou serviço foi melhor do que a esperada, o consumidor está satisfeito e a qualidade é percebida como boa. Se o produto ou serviço esteve abaixo das expectativas do consumidor, este pode estar insatisfeito, então a qualidade percebida é pobre. Se o produto ou serviço corresponde às expectativas, a qualidade é percebida como aceitável. De forma resumida tem-se que:

a) expectativa < percepção = a qualidade percebida é boa;

b) expectativa $>$ percepção $=$ a qualidade percebida é pobre/baixa;

c) expectativa $=$ percepção $=$ a qualidade percebida é aceitável.

Cabe destacar que são diversas as ferramentas utilizadas com o fim de produzir a qualidade, para que esta venha a satisfazer as necessidades tanto dos clientes quanto da própria organização. Entre elas, cita-se: a padronização, os índices de controle, os Círculos de Controle de Qualidade (CCQ), o Método de Análise e Solução de Problemas (MASP) e o 5S.

Segundo Silva (1994), o programa 5 S é considerado a base para a Qualidade Total, pois sua implantação torna o ambiente da empresa mais organizado, seguro e humano, diminuindo os desperdícios e melhorando o ambiente físico, sem sua implementação o programa de qualidade seria muito mais difícil, para não dizer impossível, de evoluir. Por meio da união das pessoas e a participação de todos, pressupostos de um programa de Qualidade Total tornam-se objetivos relativamente fáceis de se atingir. O programa $5 S$ é constituído por cinco atividades seqüenciais e cíclicas iniciadas pela letra "S", quando nomeadas em japonês. São elas: Seiri, Seiton, Seiso, Seiketsu e Shitsuke. As quais serão apresentadas de forma mais detalhada na seqüência do trabalho.

\subsection{O programa $5 S$}

Surgiu no Japão na década de 1950 e foi aplicado após a Segunda Grande Guerra, com a finalidade de reorganizar o país quando vivia a chamada crise da competitividade. A adoção do Programa 5S foi um dos fatores da recuperação das empresas japonesas e da implantação da Qualidade Total no país. Demonstrou ser tão eficaz que até hoje é considerado o principal instrumento de gestão da qualidade e da produtividade utilizado no Japão. As empresas japonesas consideram indispensável a aplicação do Programa 5S para a plena consolidação do gerenciamento pela Qualidade Total de seus empreendimentos. Foi desenvolvido com o objetivo de transformar as atitudes das pessoas e os ambientes das organizações, ocasionando melhor qualidade de vida dos funcionários, redução de custos e desperdícios e aumento da produtividade das organizações (REBELLO, 2005).

No Brasil, muitas empresas já adotaram o programa 5S. Segundo Ribeiro (1994), atualmente as empresas no Brasil se vêem obrigadas a desenvolver um papel educador em busca da qualidade total, e o 5S, adaptado à cultura de cada uma, é um método que se mostra bastante apropriado para este fim. Suas principais características são: a prática na própria atividade, simplicidade e respeito ao grupo.

Como a implantação do Programa 5S visa à qualidade de vida do indivíduo, compatibilizando os recursos disponíveis com as atividades que desenvolvem, a qualidade de vida está diretamente relacionada com o uso correto dos recursos à sua disposição, o que pode ser mais bem compreendido a partir do detalhamento do significado de cada senso, conforme apresentado a seguir. 


\subsection{Os cinco sensos do programa 5S}

Lapa (1998) menciona que o termo "Senso" significa o exercício da capacidade de apreciar, julgar e entender, ou seja, a aplicação correta da razão para julgar ou raciocinar em cada caso particular.

Conforme já descrito anteriormente, a denominação $5 \mathrm{~S}$ vem das iniciais das cinco palavras de origem japonesa: Seiri, Seiton, Seiso, Seiketsu e Shitsuke, que são as máximas do movimento. Segundo Ribeiro (1994), foi adequado à língua portuguesa na forma de cinco sensos: de organização (descarte), de ordenamento (ordenação), de limpeza (saúde), de asseio (padronização) e de disciplina (manutenção da ordem), como se pode observar na seqüência.

Seiri - Organização: senso de seleção, utilização, descarte, arrumação

Organizar é separar aquilo que é necessário dos desnecessários, dando um destino para o que deixa de ser útil para aquele ambiente. Possibilita uma melhor organização do local, criação de novos espaços, diminuição da perda de tempo e desperdício de recursos. Para a arrumação do setor, deve-se: classificar os itens (necessários e desnecessários), verificar a freqüência de uso e dar a destinação dos itens de acordo com a freqüência de uso.

Para Lapa (1998), o senso de utilização pressupõe que, além de identificar os excessos e/ou desperdícios, as pessoas estejam também preocupadas em identificar o "porquê do excesso", de modo que estas venham a adotar medidas preventivas para evitar um novo acumulo de materiais, isso é denominado de "bloqueio das causas", e esta fase da organização tem como benefícios:

- reduzir a necessidade de espaço físico, de estoque e de gasto com sistema de armazenamento;

- facilitar o arranjo físico, o controle de produção e a execução do trabalho no tempo previsto;

- diminuir o desperdício de material;

- reduzir custos e acidentes.

\section{Seiton - Ordenamento: senso de ordenação, organização, sistematização}

Ordenar é guardar as coisas necessárias, de acordo com a facilidade de acessá-las, levando em conta a freqüência de utilização, o tipo e o peso do objeto, como também uma seqüência lógica já praticada ou de fácil assimilação. Quando se tenta ordenar as coisas, necessariamente o ambiente fica mais arrumado e produtivo.

É bom refletir que a prática da organização e do ordenamento fornece extraordinários subsídios para melhorar qualquer processo.

Lapa (1998) descreve o significado do senso de ordenação de forma popular como, "cada coisa no seu devido lugar", e esta fase da ordenação tem como benefícios:

- propiciar melhor aproveitamento dos espaços existentes;

- proporcionar rapidez e facilidade na busca de itens;

- evitar desperdício de material e reduzir custos;

- contribuir para o aumento da motivação e da produtividade das pessoas;

- propiciar maior racionalização do trabalho;

- tornar o ambiente de trabalho funcional e agradável. 


\section{Seiso - Limpeza: senso de inspeção, zelo}

Limparé eliminar a sujeira, inspecionando para descobrir e atacar as fontes de problemas. A limpeza deve ser encarada como uma oportunidade de inspeção e de reconhecimento do ambiente. Para tanto, é de fundamental importância que a limpeza seja feita pelo próprio usuário do ambiente ou pelo operador da máquina ou equipamento. A limpeza é o monitoramento do ambiente, dos equipamentos e das pessoas. Para Lapa (1998), os benefícios da limpeza são: produtividade;

- proporcionar o aumento da auto-estima e da disposição da equipe gerando

- favorecer o companheirismo, a amizade e o bom humor da equipe;

- propiciar a satisfação e eficiência das pessoas;

- evitar danos à saúde da equipe e gastos com doenças;

- evitar perdas de material;

- evitar danos a equipamentos;

- melhorar a imagem interna e externa da empresa;

- reduzir condições inseguras.

\section{Seiketsu - Asseio: senso de saúde, higiene}

Segundo Calegare (1999), manter o asseio é conservar a higiene, tendo o cuidado para que os estágios de organização, ordem e limpeza, já alcançados, não retrocedam. Isto é executado através da padronização de hábitos, normas e procedimentos. O objetivo da padronização é fazer com que todas as tarefas sejam cumpridas voluntária e rotineiramente da mesma forma, para que os resultados sejam sempre aqueles esperados, a fim de melhorar o desempenho da organização. É o ponto alto do método.

É preciso que haja um sólido compromisso de toda a equipe para a mudança de hábito, a fim de que as boas condições sejam mantidas. Isso implica em educação das pessoas. Para Lapa (1998) os benefícios da conservação são:

- melhoria contínua do ambiente de trabalho;

- racionalização do tempo;

- incentivo à criatividade das pessoas envolvidas;

- melhoria da produtividade;

- base para a Qualidade Total.

Shitsuke - Disciplina: senso de educação, manutenção da ordem, comprometimento

Ser disciplinado é cumprir rigorosamente as normas e tudo o que for estabelecido pelo grupo. A disciplina é um sinal de respeito ao próximo.

Lapa (1998) afirma que ter senso de disciplina é desenvolver o hábito de observar e seguir normas e regras, tanto escritas quanto informais, e que este hábito é o resultado do exercício da força mental, moral e física. Os benefícios da disciplina são:

- melhoria das relações humanas;

- favorecimento do trabalho em equipe;

- confiabilidade e credibilidade das informações;

- eliminação do desperdício;

- dignificação do ser humano;

- facilidade de execução de todas as tarefas. 
Para Calegare (1999), o programa 5 S é basicamente a determinação de arrumar e organizar um local de trabalho, de manter arrumado e limpo, de manter as condições padronizadas e a disciplina necessária para realizar um bom trabalho. Organização, arrumação e limpeza referem-se às atividades de pessoas, padronização refere-se à execução das anteriores de forma sistematizada e disciplina refere-se à manutenção da nova ordem estabelecida. Para utilizar o 5S, é necessário que se tenha uma metodologia de implementação correta, para almejar ganhos maiores em termos de motivação, criatividade, produtividade e lucratividade. Se o líder e a equipe não tiverem motivação, certamente cairão na acomodação, que vem acompanhada de regressão e tudo o que foi implantado vai por "água abaixo". Aliás, o próprio nome é Qualidade Total e não Qualidade Parcial. A Qualidade Total só pode ser atingida se houver trabalho em grupo, com plena integração entre os colaboradores em todos os níveis da organização e com diálogo amplo e franco. As barreiras devem ser eliminadas, sejam elas físicas ou mentais.

Após a implantação de tal programa em todos os setores e com a participação de todos na organização, será necessário mantê-lo, e uma das formas é a aplicação da metodologia PDCA, ou seja, planejamento anual levando em conta as necessidades e expectativas dos usuários e funcionários, estabelecendo as metas e os métodos para alcançá-las, educando e treinando os envolvidos, executando tarefas planejadas, controlando a manutenção do que já foi implementado, verificando os resultados obtidos e aprimorando, por meio de questionários e entrevistas. Segundo Lancaster (1996, p. 8), a avaliação de um produto ou serviço será um exercício estéril se não for conduzida com o objetivo específico de identificar os meios de melhorar seu desempenho.

De uma forma simplificada, a relação entre a Ferramenta PDCA e os 5S pode ser simplificada no Quadro1:

\begin{tabular}{|c|c|c|c|}
\hline & $\mathbf{P}$ & D & A \\
\hline SENSOS & PREPARAÇÃO & IMPLANTAÇÃO & MANUTENÇÃO \\
\hline Organização & $\begin{array}{c}\text { Identificar o que é necessário } \\
\text { para execução das tarefas e } \\
\text { por que se necessita daquilo. }\end{array}$ & $\begin{array}{c}\text { Prover o que é necessário } \\
\text { para execução da tarefas e } \\
\text { descartar aquilo julgado } \\
\text { desnecessário. }\end{array}$ & \multirow{5}{*}{$\begin{array}{l}\text { Consolidar os ganhos obtidos } \\
\text { na fase de implantação de } \\
\text { forma a garantir que os } \\
\text { avanços e ganhos serão } \\
\text { mantidos. } \\
\text { Padronizar as ações de } \\
\text { bloqueio que se mostraram } \\
\text { eficazes na eliminação das } \\
\text { causas. } \\
\begin{array}{l}\text { Promover ações de bloqueio } \\
\text { contra reincidência } \\
\text { (mecanismo à prova de } \\
\text { bobeiras) }\end{array}\end{array}$} \\
\hline Ordenamento & $\begin{array}{c}\text { Definir onde e como dispor } \\
\text { os itens necessários para a } \\
\text { execução das tarefas. }\end{array}$ & $\begin{array}{c}\text { Guardar, acondicionar e } \\
\text { sinalizar de acordo com as } \\
\text { definições feitas na fase } \\
\text { anterior. }\end{array}$ & \\
\hline Limpeza & $\begin{array}{l}\text { Identificar as fontes de } \\
\text { sujeira, identificar causas, } \\
\text { limpar e planejar a } \\
\text { eliminação das fontes de } \\
\text { sujeira. }\end{array}$ & $\begin{array}{c}\text { Eliminar as fontes de } \\
\text { sujeira. }\end{array}$ & \\
\hline Asseio & $\begin{array}{c}\text { Identificar os fatores } \\
\text { higiênicos de risco nos locais } \\
\text { de trabalho e planejar ações } \\
\text { para eliminá-los. }\end{array}$ & $\begin{array}{c}\text { Eliminar os riscos do } \\
\text { ambiente de trabalho ou } \\
\text { atenuar seus efeitos. }\end{array}$ & \\
\hline Disciplina & $\begin{array}{c}\text { Identificar não- } \\
\text { conformidades os padrões } \\
\text { existentes e as oportunidade } \\
\text { de melhorias para os quatro } \\
\text { outros sensos. }\end{array}$ & $\begin{array}{c}\text { Eliminar as não- } \\
\text { conformidades encontradas } \\
\text { na fase anterior. }\end{array}$ & \\
\hline
\end{tabular}

Fonte: Lapa (1998).

Quadro 1 - Relação entre PDCA e 5S. 
Pela análise do Quadro 1, pode-se observar que está basicamente dividido em três fases denominadas de preparação, implementação e manutenção. Na fase de preparação, estão os problemas e não-conformidades identificados e aí pode-se planejar a ação de eliminação dos sintomas e causas. Esta fase institui o P de PDCA. As ações planejadas na fase anterior são executadas nas etapas $D$, que são verificadas na etapa $C$. E, por fim, a etapa A do ciclo PDCA, a padronização das ações de bloqueio contra reincidência, responsável pela manutenção, a qual é a oportunidade de consolidar os ganhos obtidos na fase de implantação, de forma a garantir que não haverá retrocessos. Este é um programa de fácil aplicação e que apóia significativamente a qualidade se bem administrado.

\section{Avicultura de corte no Brasil: uma breve contextualização}

No Brasil, de acordo com Costa (1999), a avicultura, com características modernas de comercialização, teve início já durante as décadas de 1920 e 1930, consolidando-se no final dos anos 1950. Tal consolidação somente foi possível, em nível interno, após a estruturação de novos galpões ou galinheiros, novas técnicas de manejo e alimentação animal, como também por meio de um constante aperfeiçoamento do controle sanitário e de doenças. Atualmente, segundo dados da FAO (2005), este é o terceiro maior produtor e o maior exportador mundial de carne de frango, exportando para mais de oitenta países.

A carne de frango cresceu consideravelmente nos últimos anos no Brasil, variando de um total de 5.526 toneladas, em 1999, para 8.235 toneladas em 2004. Desse total, 5.920.908 toneladas foram direcionadas para o mercado interno, e 2.115 toneladas para exportação (ABEF, 2005). O mercado interno apresenta grande potencial e verificou-se um incremento considerável no consumo per capita de frango no país, que cresceu de 29,1 kg, em 1999, para 34,2 kg em 2004 (ABEF, 2005). E, para manter um crescimento favorável, é necessário que haja empenho e dedicação dos produtores e das empresas integradoras na garantia de um produto de melhor qualidade e baixos custos.

A atividade avícola de corte é realizada por meio de modelos de integração, que pode ser do tipo vertical ou produção integrada. A integração vertical ou verticalização é o nome dado ao sistema de produção no qual o processador escolhe fazer, ele mesmo, uma etapa do processo (se for para frente, é à jusante; se for para trás, é à montante) em função da maior especificidade de ativos envolvida, freqüência, incerteza. Ocorre quando uma mesma empresa atua em mais de um estágio do processo produtivo. Isso se dá, geralmente, a partir do momento em que empresas que atuam em estágios diferentes se fundem. Produção integrada é o nome do senso comum (não científico e nem técnico) de um sistema de produção de frangos de corte, realizado em parceria, de forma contratual, entre uma indústria, cooperativa etc. (chamada de integradora) e o produtor de frangos (chamado de integrado), portanto, trata-se de um arranjo contratual, de acordo com Williamson (1996).

\section{Método de pesquisa}

No presente trabalho, optou-se pelo estudo de caso que, segundo Yin (2005), é uma estratégia de pesquisa utilizada em muitas situações, que inclui os estudos organizacionais e gerenciais, que está sendo cada vez mais adotada como ferramenta de pesquisa.

Como local para a realização desta pesquisa, foi escolhida uma Agroindústria, localizada ao Norte do estado do Rio Grande do Sul, na cidade de Marau. Essa empresa está, hoje, entre as grandes empregadoras do país, com aproximadamente 33.000 funcionários, mantém parceria 
com cerca de 5.700 produtores integrados e exporta seus produtos para mais de cem países. Dentre suas atividades estão: granjas de aves e suínos, incubatórios, sistema de integração com produtores rurais, fábricas de rações, abate e processamento de aves e suínos, congelados e industrializados, comercialização de vegetais, indústria de óleo de soja e reflorestamento.

Essa Agroindústria possui quinze unidades industriais de carnes, localizadas nos estados do Rio Grande do Sul, Paraná, Santa Catarina, Goiás e Mato Grosso. Dispõe de uma das maiores redes de distribuição de congelados e refrigerados do País, que abrange 95\% do território nacional, suportada por dezesseis centros de distribuição próprios e treze terceirizados. No exterior, possui escritórios comerciais na Inglaterra, Holanda, Emirados Árabes Unidos, Cingapura, Japão e França.

A empresa apresentou interesse e concedeu uma maior abertura para a realização da pesquisa, pois reconhece a necessidade de ter um maior conhecimento sobre a real situação em que se encontra a aplicação do Programa de Qualidade Total Rural (QTR), ou seja, conhecer a qualidade percebida dos integrados com relação ao QTR, a expectativa e percepção dos integrados com os requisitos exigidos pelo programa, e os requisitos que apresentam uma maior dificuldade em sua aplicação no programa QTR.

Para isso, o estudo se delineou em duas fases. A primeira consistiu do levantamento e revisão da bibliografia existente sobre os temas contemplados na pesquisa. Na segunda fase, coletou-se os dados utilizados no estudo através de fontes primárias e secundárias. Para coleta de dados secundários, foram utilizados documentos já existentes na empresa. Já os dados primários foram obtidos por meio de questionário semi-estruturado, a partir da avaliação da expectativa e percepção dos produtores rurais integrados com relação aos requisitos do Programa de Qualidade Total Rural, os quais estão descritos de forma mais detalhada no Quadro 2.

Foi utilizada uma escala do tipo Likert de cinco pontos, tanto para a expectativa como para a percepção. A expectativa foi pesquisada a partir de uma escala de importância (1 para insignificante e 5 para extremamente importante) e a percepção através de uma escala de desempenho (1 para péssimo e 5 para excelente).

A população de estudo é formada pelos produtores rurais integrados (avicultura) da empresa estudada - na Regional RS, sediada na cidade de Marau, que no momento da realização da pesquisa totalizava 1.100 integrados. Com base nisso, foi selecionada uma amostra aleatória probabilística para a realização da pesquisa, com um nível de confiança de 95\% e um erro amostral de $3 \%(0,15$ pontos referentes à escala utilizada), sendo a amostra composta de 100 produtores rurais.

Com base no exposto acima, foi realizada uma análise comparativa entre a expectativa e a percepção dos produtores rurais com relação ao programa de Qualidade Total Rural. É relevante mencionar que a análise e interpretação dos dados se deu a partir da estatística descritiva, o que possibilitou o alcance dos objetivos. 


\begin{tabular}{|c|c|c|}
\hline$" 5 \mathrm{~S}^{\prime \prime}$ & & REQUISITOS \\
\hline \multirow[t]{2}{*}{$\begin{array}{l}\text { Senso de } \\
\text { Seleção }\end{array}$} & \multirow[t]{2}{*}{$\begin{array}{l}\text { Descarte de } \\
\text { materiais }\end{array}$} & $\begin{array}{l}\text { 1- Faz o descarte correto do material servível e não-servível (focar } \\
\text { pocilga/aviário). }\end{array}$ \\
\hline & & 2- Área de descarte (tem e usa). \\
\hline \multirow{15}{*}{$\begin{array}{l}\text { Senso de } \\
\text { Ordenação }\end{array}$} & \multirow[t]{3}{*}{ Ordenação } & 3- Interna (pocilga/aviário). \\
\hline & & 4- Externa (fora das instalações/propriedade). \\
\hline & & 5- Ordenação do escritório/armário p/ medicamentos/documentação. \\
\hline & \multirow[t]{2}{*}{ Identificações } & 6- Interna (pocilga/aviário), pontos de pesagem/no de baias. \\
\hline & & 7- Externa (casinha da entrada, placas de localização/sinalização). \\
\hline & \multirow[t]{10}{*}{ Equipamentos } & 8- Comedouros ( $\mathrm{n}$ - , estado, distribuição etc.). \\
\hline & & 9- Bebedouros (dosador/clorador/tubulação/caixa d'agua/fonte etc.). \\
\hline & & 10- Ventiladores/nebulizador( $\mathrm{n} \cong$, instalação, funcionamento etc.). \\
\hline & & 11- Cortinado(pinteiro padrão/leitoeiro/externo com envelope/creche/etc.). \\
\hline & & 12- Iluminação (no/funcionamento/timer/iluminação do pinteiro). \\
\hline & & $\begin{array}{l}\text { 13- Aquecimento (quantidade/estado/estrados SVT/escamoteador/pré- } \\
\text { creche). }\end{array}$ \\
\hline & & $\begin{array}{l}\text { 14- Silo (capacidade/vedação/conservação/forração interna dos silos de } \\
\text { madeira). }\end{array}$ \\
\hline & & 15- Depósito de equipamentos (aviário/pocilga). \\
\hline & & 16- Local p/ amostra de ração. \\
\hline & & 17-Termômetro (máxima e mínima). \\
\hline \multirow[t]{17}{*}{ Limpeza } & \multirow{4}{*}{$\begin{array}{l}\text { Roedores } \\
\text { Galinhas } \\
\text { Pombas }\end{array}$} & $\begin{array}{l}\text { 18- Pontos de iscagem (no/estado de conservação/localização/planilha de } \\
\text { controle). }\end{array}$ \\
\hline & & 19- Evidências de infestação (locais propícios de disseminação). \\
\hline & & 20- Presença de insetos (moscas, cascudinho, piolhos, borrachudos etc.). \\
\hline & & 21- Presença de galinhas caipiras/pombas/patos (P. RISCO). \\
\hline & \multirow[t]{7}{*}{ Limpeza } & 22- Interna (pocilga/aviário). \\
\hline & & 23- Pátios e arredores das granjas. \\
\hline & & 24- Comedouros/bebedouros/eucatex/cortinados/filtros/silo/etc. \\
\hline & & 25- Pinturas padrão (externa/interna). \\
\hline & & 26- Acessos as granjas (encarretador/espaços p/ manobras). \\
\hline & & 27- Lixeiras (tem e as usa corretamente). \\
\hline & & 28- Apresentação geral da propriedade. \\
\hline & \multirow[t]{3}{*}{ Meio Ambiente } & 29-Embalagens agrotóxicos (destino correto e local ideal p/ armazenar). \\
\hline & & 30- Lixo reciclável (destino adequado). \\
\hline & & 31- Licença ambiental (LO ou protocolo). \\
\hline & \multirow[t]{3}{*}{ Ambiência } & 32- Quantidade e Qualidade da cama. \\
\hline & & 33- Arborização (plantada e conduzida), grama ao redor das instalações. \\
\hline & & 34- Condição das instalações (estrutura). \\
\hline \multirow[t]{2}{*}{ Bem-Estar } & \multirow[t]{2}{*}{ Relacionamento } & 35- Pontos de riscos de acidentes de trabalho. \\
\hline & & $\begin{array}{l}\text { 36- Participação em palestra e reuniões, compreensão das orientações } \\
\text { técnicas/QTPr. }\end{array}$ \\
\hline $\begin{array}{l}\text { Auto- } \\
\text { Disciplina }\end{array}$ & Administração & 37- Preenchimento de documentos relativos à atividade. \\
\hline
\end{tabular}

Fonte: Intranet da Agroindústria (2005), adaptado pelos autores.

Quadro 2 - Requisitos avaliados no Programa de Qualidade Total Rural.

\section{Apresentação dos resultados}

Foram pesquisados 100 integrados, selecionados através de uma amostra aleatória probabilística. Dentre estes, cerca de $48 \%$ fazem parte da integração de um a cinco anos, e $52 \%$ com mais de cinco anos. De forma geral, consideram a aplicabilidade do Programa 
de Qualidade Total Rural (QTR) muito importante para um melhor desenvolvimento da propriedade. Na seqüência, serão discutidas as variáveis primárias e secundárias, pesquisadas e que foram abordadas no modelo teórico do trabalho. As primárias se referem aos cinco sensos (5S), e as secundárias são os requisitos que compõem cada senso. Para cada variável pesquisouse a expectativa atribuída pelo integrado bem como sua percepção. Com isso, pôde-se, ao final do trabalho, analisar a percepção dos integrados com relação aos requisitos do programa de Qualidade Total Rural (QTR), bem como verificar as reais dificuldades encontradas na aplicação de cada requisito, como pode ser visto na seqüência.

A primeira variável analisada foi o senso de seleção, que é composto por dois requisitos: fazer o descarte correto de materiais, o qual, através de sua análise, pôde-se perceber que cerca de $88 \%$ dos integrados avaliaram sua expectativa entre importante e muito importante, e $72 \%$ destes avaliaram sua percepção entre bom e muito bom. Mesmo com tais resultados, vale destacar que a avaliação da percepção permaneceu inferior à expectativa. O segundo requisito - área de descarte - apresentou uma variabilidade de respostas na expectativa de aproximadamente $23 \%$, apresentando avaliações de pouco a extremamente importante e mantendo-se, em média, entre importante e muito importante, com $86 \%$ das respostas, sendo que $2 \%$ dos integrados questionados o avaliaram como nada importante. Já a percepção manteve sua avaliação em média entre bom e muito bom, com $84 \%$ de respostas e com uma variabilidade de aproximadamente $22 \%$, que foram desde regular até excelente É válido destacar que nenhum dos integrados questionados avaliou sua percepção como péssima, porém, ainda assim, esta se manteve abaixo da expectativa.

De forma geral, este senso é considerado importante, apesar de apresentar $2 \%$ das avaliações referentes ao requisito área de descarte como nada importante. Já a percepção, em ambos os requisitos, manteve sua principal avaliação em bom. Contudo, percebe-se que foram avaliados, em média, inferior à expectativa, ou seja, a qualidade percebida é baixa e isto dá indícios de que é necessário, por parte da organização integradora, atividades para melhorar a aplicabilidade deste senso e, mais especificamente, de seus requisitos nas propriedades rurais.

A segunda variável analisada foi o senso de ordenação, o qual, dentro do programa de Qualidade Total Rural, apresenta os seguintes requisitos a serem avaliados: ordenação interna do aviário; ordenação externa do aviário; ordenação de escritório, armário para medicamentos e documentação; fazer identificação interna (pontos de passagem, armários etc.); identificação externa da propriedade; ordenação dos comedouros; ordenação dos bebedouros; ordenação dos ventiladores e nebulizadores; ordenação do cortinado; ordenação da iluminação; ordenação do aquecimento; ordenação do silo; ordenação do depósito de equipamento do aviário e ordenação do local para amostra de ração e ordenação do termômetro. Dentre esses, apenas um apresentou a percepção superior à expectativa. Também vale destacar que alguns se sobressaíram por apresentar um maior grau de dificuldade em seu desempenho conforme será destacado a seguir.

O requisito "Ordenação de escritório, armário para medicamentos e documentação" apresentou um maior destaque, pois, diferente dos demais, a avaliação da percepção dos produtores rurais foi considerada superior à expectativa desse requisito, ou seja, cerca de 91\% avaliaram sua percepção entre bom e muito bom; e a expectativa manteve-se entre importante e muito importante, com $85 \%$ de suas respostas. Sendo assim, pode-se dizer que os integrados estão satisfeitos em relação à qualidade percebida deste requisito, superando suas expectativas.

Quanto ao requisito "Ordenação do depósito de equipamento do aviário", a expectativa apresentou uma variação de $23 \%$ em suas respostas, mantendo-as de nada à extremamente importante, atingindo os dois extremos, ou seja, ao mesmo tempo que alguns 
dos integrados questionados consideram o requisito extremamente importante $(5 \%)$, outros o consideram nada importante ( $2 \%)$, sendo que a avaliação média permaneceu entre importante e muito importante, totalizando $86 \%$ de respostas. Referindo-se à percepção, verificou-se que as respostas apresentaram o mesmo tipo de avaliação, indo de péssimo a excelente, porém esta apresentou uma variabilidade de respostas mais elevada, com aproximadamente $26 \%$, portanto, com maior divergência na percepção dos produtores rurais. E sua avaliação permaneceu, em média, entre bom e muito bom, com $76 \%$ de respostas. Percebe-se, então, que a expectativa apresentou sua avaliação superior à percepção, indicando insatisfação diante da qualidade percebida deste requisito.

No requisito "Ordenação do local para amostra de ração", a expectativa apresentou uma variabilidade de aproximadamente $23 \%$ em suas respostas, as quais se mantiveram de nada importante a extremamente importante, tendo a média entre importante e muito importante, com $85 \%$ de respostas. Vale destacar que, apesar de um $1 \%$ dos pesquisados avaliarem o requisito como nada importante, o destaque principal permaneceu em importante. Já relacionado à percepção, esta apresentou uma variação de respostas de aproximadamente $21 \%$, desde regular à excelente e, em média, manteve-se entre bom e muito bom, com $84 \%$ de respostas, sendo que nenhum dos integrados avaliou o seu desempenho no requisito em estudo como péssimo. Mesmo com uma diferença mínima, a expectativa permaneceu superior à percepção, apresentando uma qualidade percebida considerada baixa.

O requisito "Ordenação do termômetro", por sua vez, apresentou, na avaliação da expectativa, uma variabilidade de aproximadamente $24 \%$ em suas respostas, mantendoas de pouco importante a extremamente importante, sendo que a média permaneceu entre importante e muito importante, com $79 \%$ de respostas, não havendo nenhum dos integrados questionados avaliando-a como nada importante. A percepção, por sua vez, manteve suas respostas de regular a excelente, apresentando uma variabilidade de aproximadamente $22 \%$, mantendo-se, em média, entre bom e muito bom, com respectivamente $84 \%$ de respostas e nenhuma avaliação como péssimo.

Em geral, o senso manteve a maior parte das avaliações de seus requisitos, apresentando a expectativa superior à percepção, o que demonstra que a qualidade percebida é considerada pobre, talvez fosse necessário que a empresa integradora buscasse apresentar, de forma prática, aos integrados como realizar os requisitos. Uma das maneiras possíveis seria realizando mais dias de campo, com o intuito de demonstrar a melhor maneira ou a forma correta de se desempenhar os requisitos pertencentes a este senso.

A terceira variável analisada foi o senso de limpeza, este senso, dentro do programa de Qualidade Total Rural, traz consigo os requisitos: ponto de iscagem; evidência de infestação; presença de insetos; presença de galinhas caipiras, pombos e patos; limpeza interna do aviário, limpeza dos pátios e arredores da granja; limpeza de comedouros, bebedouros, eucatex, cortinados, filtros, silos etc.; pintura padrão externa e interna; acesso às granjas; lixeiras; apresentação geral das propriedades; tratamento de dejetos e embalagens de agrotóxicos e lixo reciclável, licença ambiental, quantidade e qualidade da cama, arborização, condições das instalações.

O requisito "lixo reciclável" apresentou um maior destaque dos demais pertencentes ao senso, quando relacionado ao grau de dificuldade de sua realização, pois, na concepção dos integrados, diante da expectativa, estes o avaliaram em média entre importante (com 46\%) e muito importante (com $38 \%$ de respostas), sendo que variaram, em aproximadamente $22 \%$, de pouco importante a extremamente importante. A percepção manteve-se, em média, entre bom e muito bom com $73 \%$ das avaliações. Suas respostas foram de regular a excelente, com uma variabilidade de aproximadamente $26 \%$. Por meio desses dados, verificou-se que a expectativa manteve-se superior à percepção.

Rev. Adm. UFSM, Santa Maria, v. I, N. 1, P. 153-170, JAN./ABr. 2008 
Após realizar as análises de expectativa e percepção dos integrados em relação a cada requisito pertencente ao senso de limpeza, pôde-se observar que todos eles apresentaram a avaliação da expectativa superior à obtida com a percepção, ou seja, os integrados estão com suas expectativas além do que estão realmente desempenhando, portanto, a qualidade percebida é baixa, insatisfatória. Uma ação de melhoria poderia ser a organização integradora reforçar a forma correta de como devem ser executados os requisitos pertencentes a este senso.

A quarta variável analisada foi o senso de bem-estar, o qual apresenta, dentro do programa de Qualidade Total Rural, os requisitos: ponto de risco de acidente de trabalho, participação em palestras e reuniões e compreensão das orientações técnicas do QTR. Como nos demais sensos, o mesmo ocorreu com o senso de bem-estar, o qual os integrados avaliaram seus requisitos mantendo a expectativa superior à percepção, apresentando uma baixa qualidade percebida. Mais uma vez salienta-se a necessidade da integradora reforçar a maneira correta de como devem ser executados os requisitos pertencentes ao senso em análise.

A quinta e última variável analisada foi o senso de auto disciplina, este senso dentro do programa de Qualidade Total Rural abrange o requisito a ser avaliado: preenchimento de documentos relativos a atividade. Com a análise deste requisito, observou-se que o senso de autodisciplina também se inclui ao grupo dos demais sensos apresentados, obtendo o resultado da expectativa superior à percepção, demonstrando a insatisfação com a qualidade percebida.

Após realizar a análise de cada um dos requisitos pertencentes aos sensos, com o intuito de se finalizar a discussão, foi construída uma tabela, a qual apresenta, de forma resumida, as médias obtidas em cada senso, ou seja, foram calculadas as médias da expectativa e percepção dos requisitos que compõem cada senso. Também é exposto o GAP de cada senso, referente ao nível de qualidade percebida dos produtores rurais integrados, calculado por meio da diferença entre a expectativa e a percepção dos produtores rurais em cada senso. A última média apresentada na tabela é a média geral obtida entre todos os sensos, como pode ser observado na Tabela 1.

Tabela 1 - Expectativa e percepção de cada senso dos integrados da agroindústria estudada

\begin{tabular}{|c|r|c|c|}
\hline Sensos & Expectativa & Percepção & $\begin{array}{c}\text { Qualidade Percebida } \\
\text { (GAP) }\end{array}$ \\
\hline Senso de Seleção & 3,41 & 3,20 & $-0,21$ \\
\hline Senso de Ordenação & 3,57 & 3,42 & $-0,15$ \\
\hline Senso de Limpeza & 3,58 & 3,46 & $-0,12$ \\
\hline Senso de Bem-Estar & 3,77 & 3,54 & $-0,23$ \\
\hline $\begin{array}{c}\text { Senso de Auto- } \\
\text { Disciplina }\end{array}$ & 3,41 & 3,20 & $-0,21$ \\
\hline Média & $\mathbf{3 , 5 5}$ & $\mathbf{3 , 3 6}$ & $\mathbf{- 0 , 1 9}$ \\
\hline
\end{tabular}

Fonte: dados da pesquisa.

De forma geral, tem-se que a expectativa permaneceu superior à percepção dos produtores rurais em todos os sensos do programa. Isso indica uma qualidade percebida baixa, ou seja, insatisfação dos integrados com relação ao seu próprio desempenho no QTR. Verifica- 
se que, na média, a maior expectativa foi com relação ao senso de bem-estar, sendo este também o de maior percepção. No entanto, percebe-se o maior GAP dentre todos os sensos, portanto, a qualidade percebida é a mais baixa, com maior insatisfação.

Por outro lado, a menor expectativa ficou com os sensos de seleção e autodisciplina, que também tiveram a menor percepção. Sendo esses sensos responsáveis pela segunda menor qualidade percebida. Os sensos de ordenação e limpeza permaneceram, respectivamente, com a terceira e quarta menor qualidade percebida.

Portanto, através da análise do GAP, pode-se hierarquizar os níveis de satisfação dos integrados em relação à qualidade percebida. O senso que demonstrou uma maior urgência na tomada de providências foi o de bem-estar; na seqüência, vieram os sensos de seleção e autodisciplina, depois o senso de ordenação e, por fim, o senso de limpeza. Porém, vale destacar que o GAP foi calculado sobre a média geral de cada senso. Caso fossem realizadas análises dos requisitos pertencentes a cada senso individualmente, o resultado poderia ser alterado, no sentido de mesclar na priorização de ações requisitos de diversos sensos.

Assim, foram selecionados os requisitos que mais se destacaram por apresentarem uma maior dificuldade em sua aplicação. O primeiro está relacionado com a compreensão das orientações técnicas do QTR, que faz parte do senso de bem-estar. Outro requisito é a área de descarte, pertencente ao senso de seleção, no qual se verificou que muitos justificam a dificuldade de aplicação pelo fato de haver outras possibilidades de se descartar os materiais que não estão sendo utilizados, e uma delas seria através da queima.

Quanto ao senso de ordenação, os requisitos que necessitam uma maior atenção em se tratando da avaliação da percepção foram: a ordenação do depósito de equipamentos do aviário, ordenação do local para amostra de ração e ordenação do termômetro. Os produtores argumentam que as atividades relacionadas a esses requisitos são menos importantes que outras na propriedade. Já relacionado ao senso de limpeza, o requisito que apresentou uma maior dificuldade em sua aplicação foi o requisito lixo reciclável, pelo fato de os produtores justificarem falta de tempo ou então por existirem coisas mais urgentes e importantes a se fazer.

A Figura 1 ilustra graficamente os níveis de qualidade percebida em cada senso pesquisado, ressaltando o já exposto, ou seja, que os produtores rurais integrados estão insatisfeitos com o seu próprio desempenho nos requisitos do Programa de Qualidade Rural.

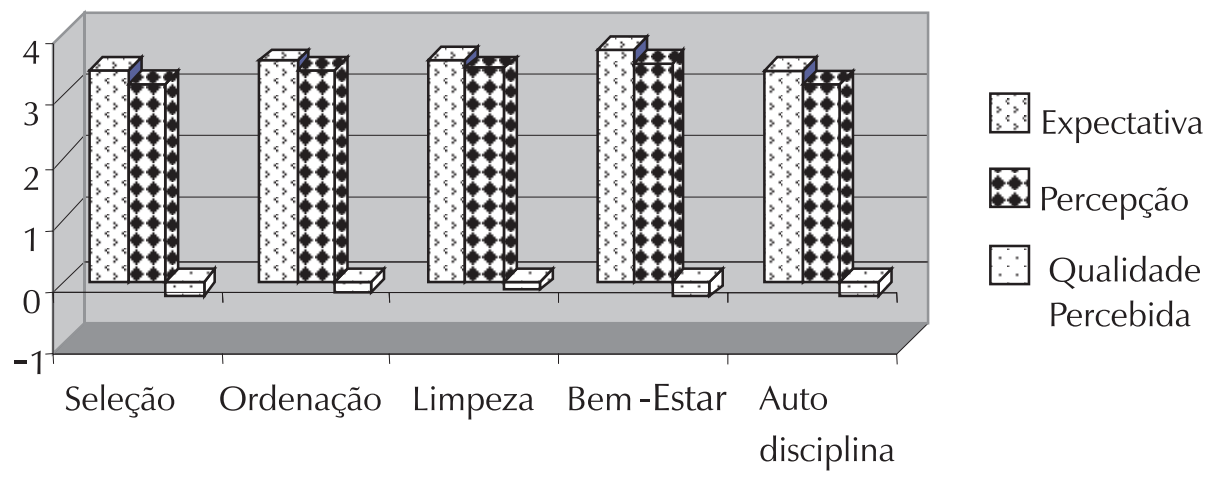

\section{Sensos}

Fonte: Dados da pesquisa

Figura 1 - Demonstração da expectativa e percepção dos integrados da agroindústria. 
Destaca-se o fato de que todos os sensos concentraram sua avaliação, no caso da expectativa, entre importante e muito importante, e, no caso da percepção, entre bom e muito bom. Isso demonstra, de forma geral, a baixa discrepância entre os sensos do QTPR na percepção dos produtores rurais integrados.

\section{Conclusão}

Com o objetivo de se identificar a qualidade percebida dos produtores rurais em relação ao Programa de Qualidade Total Rural (QTR), de uma forma geral, todos os cinco sensos que compõem o programa apresentaram a expectativa superior à percepção, ou seja, os integrados reconhecem a importância de cada senso para um melhor rendimento do trabalho, porém não desempenham os requisitos nos níveis desejados por eles. Seria necessário que a organização integradora realizasse atividades para a melhoria do desempenho dos produtores rurais integrados nos requisitos pertencentes a cada senso, bem como o reconhecimento da importância dos requisitos para o sucesso do Programa QTR e, conseqüentemente, da atividade.

Os requisitos que mais se destacaram, em ordem de prioridade, por apresentarem uma maior dificuldade em sua aplicação foram: compreensão das orientações técnicas do QTR (senso de bem-estar), área de descarte (senso de seleção), ordenação do depósito de equipamentos do aviário, ordenação do local para amostra de ração e ordenação do termômetro (senso de ordenação), lixo reciclável (senso de limpeza).

Uma das maneiras de se realizar o processo de melhoria e, após isso, dar continuidade e mantê-lo sempre em ordem, seria com a aplicação da metodologia PDCA (Planejar, Dirigir, Controlar e Agir), a qual foi mais bem apresentada no referencial teórico desta pesquisa.

Baseando-se nisso, reconhece-se que gerenciar adequadamente uma propriedade rural é uma tarefa de relativa complexidade. Reconhece-se também a importância da qualidade do produto ali produzido para o desempenho de toda a cadeia proveniente deste. Nesse sentido, destaca-se o papel fundamental que pode ser exercido pela atividade de Gestão da Qualidade numa propriedade rural, a fim de garantir a qualidade e a segurança desse produto tão suscetível a contaminações e perdas.

Conforme apresentado ao longo deste trabalho, a Gestão da Qualidade se concretiza, na prática, pelo desenvolvimento e implantação dos chamados Programas da Qualidade. Nesse contexto, é que a Agroindústria estudada buscou desenvolver um Programa específico para as propriedades rurais, com a finalidade principal de contribuir para a garantia da qualidade do frango ali produzido e para a melhoria dos processos produtivos e gerenciais, promovendo a redução de custos com perdas e retrabalhos na propriedade rural.

Por fim, a gestão da qualidade na cadeia de produção de frango é de suma importância, não somente para proporcionar melhoria na qualidade do produto final, que é um ponto inquestionável, mas também no que diz respeito à melhoria nas práticas e procedimentos das atividades que compõem toda a cadeia, a fim de reduzir perdas, desperdícios e, conseqüentemente, custos. 


\section{Referências bibliográficas}

ABEF. Associação Brasileira dos Produtores e Exportadores de Frango. Disponível em: < http:// www.abef.com.br $>$. Acesso em: 05 de nov. 2005.

CALEGARE, A. J. de A. Os mandamentos da qualidade total. 3. ed. Barueri: Inter-Qual International Quality Systems, 1999.

COSTA, P.T.C. Avaliação econômica do frango de corte na fase final. In: CONFERÊNCIA APINCO DE CIÊNCIA E TECNOLOGIA AVÍCOLAS, 1999, Campinas. Anais... Campinas: FACTA, 1999, p.71-82.

DEMING, W.E. Qualidade: a revolução da administração. Rio de Janeiro: Marques Saraiva, 1990.

FALCONI, V.C. Controle da qualidade total (no estilo japonês). Rio de Janeiro: Block, 1995.

\section{Controle da qualidade total (no estilo}

japonês). Nova Lima, MG: INDG Tecnologia e Serviço Ltda., 2004.

FAO. Food and Agriculture Organization of the United Nations. Faostat. Roma, 2005. Disponível em: < http://faostat.fao.org/faostat/collections?su bset $=$ agriculture $>$. Acesso em: 26 set. 2005.

GARVIN, David A. Gerenciando a qualidade: a visão estratégica e competitiva. Rio de Janeiro: Qualitymark, 1992.

IBGE: Banco de dados. Disponível em: < http:// www.ibge.gov.br>. Acesso em: 27 ago. 2006.

JURAN, J.M. Planejamento para a qualidade. 2. ed. São Paulo: Pioneira, 1992.

JURAN, J.M. Juran na liderança pela qualidade. São Paulo: Pioneira, 1995.

KOTLER, P. Administração de marketing: análise, planejamento, implementação e controle. 5. ed. São Paulo: Atlas, 1998.

LANCASTER, F.W. Avaliação de serviços de bibliotecas. Trad. De Antonio Agenor Briquet de Lemos. Brasília: Briquet de Lemos, 1996.
LAPA, R. P. 5S: praticando os cinco sensos. Rio de Janeiro: Qualitymark,1998.

LONGO, R. M. J.; VERGUEIRO, W. Gestão da qualidade em serviços de informação no setor público: características e dificuldades para sua implantação. Rev. Dig. Bibliotecon. Ci. Inf., Campinas, v.1., n.1, p. 39-59, 2003.

NUNES, E. P.; COTINI, E. Dimensão do complexo agroindustrial brasileiro. $A B G$ Associação Brasileira de Agrobusiness. Disponível em: <www.portaldoagronegocio.com.br/ agronegocio/agronegocio3.htm > . Acesso em: 15 set. 2005.

REBELLO, M. A de F. R. Implantação do Programa $5 \mathrm{~S}$ para a Conquista de um Ambiente de Qualidade na Biblioteca do Hosital Universitário da Universidade de São Paulo.

Rev. Dig. Bibliotecon. Ci. Inf., Campinas, v. 3, n. 1, p. 165-182, 2005. Disponível em: $<$ http://server01.bc.unicamp.br/revbib/sumario. php? vol $=2 \&$ num $=1 \&$ mes $=$ jul./dez.\&edit $=3 \&$ na $=2005>$. Acesso em: 29 nov. 2005 .

RIBEIRO, H. 5S: um roteiro para uma implantação bem sucedida. Salvador: Casa da Qualidade, 1994.

ROCHA, D. O que é agronegócio.

Disponível em: <www.noolhar.com/especiais/ agronegociosum/384562.html >. Acesso em: 15 set. 2005.

SILVA, J. E. F. Qualidade total no agronegócio. Disponível em: <www.agroline.com.br/artigos. php?id183>. Acesso em: 13 set. 2005.

SLACK, N.; CHAMBERS, S.; JOHNSTON, R. Administração da produção. 2. ed. São Paulo: Atlas, 2002.

WILLIAMSON, O. E. The mechanisms of governance. Oxford: Oxford University Press, 1996. 